\title{
Гетероструктуры для мощных ИК диодов с РБО на 850 и 920 нм методом МЛЭ
}

\author{
Солдатов Н.А. ${ }^{1}$, Дмитриев Д.В. ${ }^{2}$, Журавлев К.С. ${ }^{2}$ \\ ${ }^{1}$ Новосибирский государственный университет, 630090, Новосибирск, ул. Пирогова, 2 \\ ${ }^{2}$ ИФП СО РАН, 630090, Новосибирск, пр. Ак. Лаврентьева, 13
}

DOI 10.34077/Semicond2019-131

Излучатели инфракрасного диапазона $(\lambda=0.74-2000$ мкм) широко используются в технике ночного видения, инфракрасного освещения, дистанционного управления, видеонаблюдения и др. Однако, ввиду различных видов рассеяния и поглощения оптического сигнала в атмосфере большая часть ИК диапазона остаётся подавленной. При $\lambda=850$ и 920 нм наблюдается наименьшее затухание оптического сигнала в атмосфере. Целью работы является создание ИК диодов на 850 и 920 нм с высокой выходной мощностью.

Для увеличения выходной мощности ИК диодов предлагается поместить распределенный брэгговский отражатель (РБО) под активной областью прибора. Принцип работы РБО заключается в чередовании материалов с большим и меньшим показателями преломления, где толщины каждого выбираются такими, чтобы $\mathrm{nd}=\lambda / 4$. Так, излучение, отраженное от границ раздела двух материалов, находится в фазе, что приводит к увеличению интенсивности излучения прибора в определённом диапазоне длин волн и, следовательно, его выходной мощности. На основе литературных данных [1], РБО, выращенный на гетероструктурах $\mathrm{Al}_{0.9} \mathrm{Ga}_{0.1} \mathrm{As} / \mathrm{Al}_{0.1} \mathrm{Ga}_{0.9} \mathrm{As}$, обладает наилучшим спектром отражения по сравнению с другими материалами и составами для $\lambda=850$ и 920 нм.

Резкие гетерограницы, которые получаются в ходе роста полупроводниковых структур методом МЛЭ, являются барьерами для носителей зарядов, что может приводить к ухудшению электрооптических характеристиик излучателя. Барьеры обусловлены образованием ОПЗ, состоящего из положительно заряженного обедненного электронами слоя в широкозонном $\mathrm{Al}_{0.9} \mathrm{Ga}_{0.1} \mathrm{As}$ и отрицательно заряженного обедненного дырками слоя в $\mathrm{Al}_{0.1} \mathrm{Ga}_{0.9} \mathrm{As}$. Для их устранения было предложено создание плавного перехода на гетерогранице и модуляционное легирование гетероструктур [2].

Теоретически рассчитаны толщины слоев РБО для 850 нм: $\mathrm{L}_{\mathrm{x}=0.9}=69$ нм и $\mathrm{L}_{\mathrm{x}=0.1}=60$ нм; для 920 нм: $\mathrm{L}_{\mathrm{x}=0.9}=76$ нм и $\mathrm{L}_{\mathrm{x}=0.1}=66$ нм. Минимальное число пар слоёв необходимое для достижения коэффициента отражения $\mathrm{R}>90 \%$ составляет 25 периодов РБО.

На установке Riber Compact-21T были синтезированы тестовые образцы, измерены спектры отражения и удельные сопротивления. На основании полученных результатов разработаны подходы роста мощных излучателей на 850 и 920 нм.

[1] Su-Chang Ahn. Optimum Conditions of the Distributed Bragg Reflector in 850-nm GaAs Infrared Light-Emitting Diodes / Su-Chang Ahn, Byung-Teak Lee, Won-Chan An // Journal of the Korean Physical Society, Vol. 69, No. 1, (2016), pp. 91 95

[2] E. F. Schubert. Elimination of heterojunction band discontinuities by modulation doping/ E. F. Schubert, L. W. Tu, G. J. Zydzik, R. F. Kopf, A. Benvenuti, and M. R. Pinto// Journal of Applied Physics, 60, 466 (1992). 